OPEN ACCESS

Edited by:

Shruti Shukla,

Dongguk University, South Korea

Reviewed by:

Laxmi Ahirwal,

Dr. Hari Singh Gour University, India

Pooja Agrawal,

Madhya Pradesh Medical Council,

India

${ }^{*}$ Correspondence:

Naveen K. Kalagatur

knaveenkumar.kalagatur@yahoo.co.in

Venkataramana Mudil

ramana.micro@gmail.com

Specialty section: This article was submitted to

Predictive Toxicology,

a section of the journal

Frontiers in Pharmacology

Received: 04 September 2017

Accepted: 09 October 2017

Published: 24 October 2017

Citation:

Kalagatur NK, Karthick K, Allen JA, Nirmal Ghosh OS, Chandranayaka S, Gupta VK,

Krishna K and Mudili V (2017)

Application of Activated Carbon

Derived from Seed Shells of Jatropha

curcas for Decontamination

of Zearalenone Mycotoxin.

Front. Pharmacol. 8:760.

doi: 10.3389/fphar.2017.00760

\section{Application of Activated Carbon Derived from Seed Shells of Jatropha curcas for Decontamination of Zearalenone Mycotoxin}

\author{
Naveen K. Kalagatur ${ }^{*}$, Kumarvel Karthick ${ }^{2}$, Joseph A. Allen ${ }^{3}$, \\ Oriparambil Sivaraman Nirmal Ghosh ${ }^{4}$, Siddaiah Chandranayaka5, Vijai K. Gupta6, \\ Kadirvelu Krishna ${ }^{3}$ and Venkataramana Mudili3*
}

\begin{abstract}
' Division of Microbiology, Defence Food Research Laboratory, Mysore, India, ${ }^{2}$ Department of Civil Engineering, Bannari Amman Institute of Technology, Sathyamangalam, India, ${ }^{3}$ Center for Life Sciences, Defence Research and Development Organisation - Bharathiar University, Coimbatore, India, ${ }^{4}$ Centre for Nano-Sciences and Technology, Pondicherry University, Puducherry, India, ${ }^{5}$ Department of Biotechnology, University of Mysore, Mysore, India, ${ }^{6}$ Department of Chemistry and Biotechnology, Tallinn University of Technology, Tallinn, Estonia
\end{abstract}

In the present study, activated carbon (AC) was derived from seed shells of Jatropha curcas and applied to decontaminate the zearalenone (ZEA) mycotoxin. The AC of J. curcas (ACJC) was prepared by $\mathrm{ZnCl}_{2}$ chemical activation method and its crystalline structure was determined by $\mathrm{X}$-ray diffraction analysis. The crystalline graphitic nature of ACJC was confirmed from the Raman spectroscopy. Scanning electron microscope showed the porous surface morphology of the ACJC surface with high pore density and presence of elemental carbon was identified from the energy dispersive $\mathrm{X}$-ray analysis. From Brunauer-Emmett-Teller (BET) analysis, $\mathrm{S}_{\mathrm{BET}}$, micropore area, and average pore diameter of ACJC were calculated as $822.78\left(\mathrm{~m}^{2} / \mathrm{g}\right), 255.36\left(\mathrm{~m}^{2} / \mathrm{g}\right)$, and $8.5980(\AA)$, respectively. The adsorption of ZEA by ACJC was accomplished with varying contact time, concentration of ZEA and ACJC, and $\mathrm{pH}$ of media. The ACJC has adsorbed the ZEA over a short period of time and adsorption of ZEA was dependent on the dose of ACJC. The effect of different $\mathrm{pH}$ on adsorption of ZEA by ACJC was not much effective. Desorption studies confirmed that adsorption of ZEA by ACJC was stable. The adsorption isotherm of ZEA by ACJC was well fitted with Langmuir model rather than Freundlich and concluded the homogeneous process of sorption. The maximum adsorption of ZEA by ACJC was detected as $23.14 \mu \mathrm{g} / \mathrm{mg}$. Finally, adsorption property of ACJC was utilized to establish ACJC as an antidote against ZEA-induced toxicity under in vitro in neuro-2a cells. The percentage of live cells was high in cells treated together with a combination of ZEA and ACJC compared to ZEA treated cells. In a similar way, $\Delta \Psi_{M}$ was not dropped in cells exposed to combination of ACJC and ZEA compared to ZEA treated cells. Furthermore, cells treated with a combination of ZEA and ACJC exhibited lower level of intracellular reactive oxygen species and caspase3 compared to ZEA treated cells. These in vitro studies concluded that ACJC has 
successfully protected the cells from ZEA-induced toxicity by lowering the availability of ZEA in media as a result of adsorption of ZEA. The study concluded that ACJC was a potent decontaminating agent for ZEA and could be used as an antidote against ZEA-induced toxicity.

Keywords: activated carbon, mycotoxins, zearalenone, Jatropha curcas, decontamination, antidote

\section{INTRODUCTION}

Mycotoxins are poisonous metabolites of fungi that infest agricultural commodities at various stages of pre-harvesting and post-harvesting sessions under a wide range of weather conditions (Iqbal et al., 2016). The most important fungi responsible for contamination of mycotoxins are Aspergillus, Penicillium, Fusarium, Alternaria, and Stachybotrys (Bräse et al., 2013). The Food and Agriculture Organization (FAO) has assessed that about one fourth of agricultural commodities are affected by fungi and mycotoxins worldwide (Dall'Asta and Berthiller, 2015). Mycotoxins have a deleterious effect on the well-being of humans and livestock and their occurrence pose a great challenge concerning the food safety (Gamliel et al., 2017). Consequently, the European Union nations (EU), FAO, Joint FAO/WHO Expert Committee on Food Additives (JECFA), and many other countries have established certain regulatory limits over mycotoxins at international trade (Van Egmond et al., 2007). Therefore, the occurrence of mycotoxins in agricultural commodities is a foremost worry for farmers, consumers, and government (Udomkun et al., 2017). Till date, approximately 1000 mycotoxins were identified and their number will increase in next few years with the innovation of newer analytical techniques (Bräse et al., 2013). The five major mycotoxins that contaminate quite regular in agricultural products are aflatoxin $\mathrm{B} 1$, fumonisin $\mathrm{B} 1$, deoxynivalenol (DON), ochratoxin $\mathrm{A}$, and zearalenone (ZEA) (Richard, 2007).

The ZEA is also well known as RAL or F-2 toxin and exclusively known estrogenic mycotoxin. It is heat resistant, color and odorless, and white crystalline solid substance (Zinedine et al., 2007). The ZEA is produced by a large class of secondary metabolite pathway called polyketide synthases (PKSs) by Fusarium spp. including F. cerealis, F. crookwellense, F. culmorum, F. equiseti, F. graminearum (Gibberella zeae), and F. semitectum. These are prevalent soil-borne fungi and widely distributed in temperate and warm climates worldwide, and are regular contaminants of cereals (Zinedine et al., 2007). The accessible data across worldwide point out that maize and its by-products are the most prominent with a high occurrence of ZEA. Though, barley, oats, sorghum, rice, rye, soybean and wheat, and its by-products are found occasionally contaminated with ZEA (European Food Safety Authority [EFSA], 2004). Sometimes, ZEA has been detected in the spices, flavored ingredients, Ayurveda and herbal products, fermented products, vegetarian edible oils, beverages, and drinking water (Gromadzka et al., 2008). The food intake by means of meat and other by-products of animals fed with ZEA contaminated feed has a great health concern. The flesh of several species including chicken, turkey, duck, rabbit, pig, and cow was found to carry over low levels of ZEA and its metabolites (Creppy, 2002). The ZEA exhibits relatively low acute toxic effects and its oral LD50 doses are $>2000-20,000 \mu \mathrm{g} / \mathrm{kg}$ of body weight in mice, rats, and guinea pigs, and it was more toxic by intraperitoneal administration (Zinedine et al., 2007). The ZEA mainly affects the female reproductive system, causes immature births, abortions, and vulvovaginitis in livestock, and occasionally may be liable for hyperestrogenism in humans too (Vejdovszky et al., 2017). The International Agency for Research on Cancer (IARC) has checked the mutagenicity of ZEA under in vitro and recommended as group 3 carcinogen (IARC, 1999). In the recent studies, the toxicity of ZEA was well explored and revealed the hepatotoxicity, neurotoxicity, immunotoxicity, endocrine toxicity, carcinogenicity, and genotoxicity features (Venkataramana et al., 2014; Kowalska et al., 2016). In the present scenario, decontamination strategies to eliminate the ZEA from contaminated agricultural commodities are much needed to maintain food safety, minimize economic loss, and rescue contaminated food products. Wide varieties of decontamination methods including physical, chemical, and biological methods were applied to reduce toxic levels of ZEA (Zinedine et al., 2007; Kalagatur et al., 2015; Gottardi et al., 2016; Kumar et al., 2016). Among the physical decontamination methods, the addition of nutritionally inert sorbents to food and feed matrices is the most recent technique that has been widely suggested to reduce the toxicity of ZEA. Most of the studies connected to the mitigation of ZEA mycotoxicosis by the usage of adsorbents are primarily focused on aluminosilicates comprising of clays. Unfortunately, application of aluminosilicates for the mitigation of ZEA was a minute success. Avantaggiato et al. (2014) reported that activated carbon (AC) and cholestyramine were good adsorption agents of ZEA and can be applied as a feed additive to avoid hyperestrogenism in livestock. However, the high cost of $\mathrm{AC}$ and cholestyramine would make their use economically unaffordable (Galvano et al., 2001). Recently, development of functional nanomaterials and AC with novel physicochemical properties using inexpensive, easily available, and environmentally friendly raw materials is highly attracted research area (Kumar and Sharma, 2008; Patra and Baek, 2017). Especially, AC of Jatropha curcas has found to have extensive application in decontamination of a variety of toxic environmental contaminants (Hsu et al., 2014).

Jatropha curcas is a shrub, belongs to the family Euphorbiaceae, and native of a Central part of America and Mexico. Nowadays, it is a highly cultivated plant in tropical and sub-tropical parts worldwide. J. curcas is resistant to saline and drought and can adapt to gravelly, saline, low fertile, and arid desert conditions (Chen et al., 2016; Lama et al., 2016). The seeds of J. curcas comprise around $20 \%$ saturated and $80 \%$ 
unsaturated fatty acids and yield an average of $34.4 \%$ oil that can be used as a biodiesel. The oil is non-edible and widely used in the preparation of candles, cosmetics, detergents, and coloring agents. The oil cake was used in the preparation of synthetic fibers and plastics (Kumar and Sharma, 2008). The seed shell also contains high amounts of cellulose, hemicelluloses, and lignin and can be a rich source of AC (Hsu et al., 2014). In addition, J. curcas presented many medicinal benefits, the latex alkaloid is rich in jatrophine and has potent anticancer activity, and latex was found effective in the treatment of skin, paralysis, and rheumatoid ailment. The tender twigs and leaf juice were used as a medication for a toothache and piles, respectively, and root extracts were used as an antidote to poisonous snake bites (Kumar and Sharma, 2008). Recently, phorbol ester fraction of J. curcas seed oil has found an innovative role as bio-insecticide in crop protection (Ratnadass and Wink, 2012). Recently, Chauhan et al. (2016) has synthesized silver particles with leaf extract J. curcas and suggested to use as an antibacterial agent on a variety of food-borne bacteria. To the best of our knowledge, the decontamination of ZEA using AC derived from J. curcas is not reported yet. In this regard for the first time, we report the synthesis of porous AC with the large specific surface area by facile carbonization of seed shell of $J$. curcas and evaluation of its biological activities and effectiveness in ZEA decontamination.

\section{MATERIALS AND METHODS}

\section{Chemicals and Reagents}

The ZEA, dichloro-dihydro-fluorescein diacetate (DCFH-DA), rhodamine 123 , caspase- $3 \mathrm{kit}$, and $0.22 \mu \mathrm{m}$ of syringe filters were obtained from Sigma-Aldrich (Bengaluru, India). Acetonitrile, methanol, dimethyl sulfoxide (DMSO), and analytical grade water were obtained from Merck (Bengaluru, India). Dulbecco's modified Eagle's medium (DMEM), citrate buffer solution (CBS), an antibiotic solution of penicillin and streptomycin, fetal bovine serum (FBS), and Dulbecco's phosphate buffered saline (D-PBS) were obtained from HiMedia (Mumbai, India). Live/dead cell assay detection kit was obtained from Invitrogen Detection Technologies (Bengaluru, India), and plastic ware for cell culture was obtained from Nunc (Bengaluru, India).

\section{Synthesis of Activated Carbon}

The seeds of J. curcas was collected from Tamil Nadu region, India, and washed thoroughly with distilled water, and dried for 2 weeks at room temperature. The husk was separated from the seeds and crushed into a fine powder at a particle size of $500 \mu \mathrm{m}$ with a micro hammer mill. A quantity of $450 \mathrm{~g}$ fine powder was blended with hot distilled water containing $450 \mathrm{~g}$ of $\mathrm{ZnCl}_{2}$ for $1 \mathrm{~h}$ and dried out at $60 \pm 5^{\circ} \mathrm{C}$ in a hot-air oven. The leftover material was filled in a steel container with a tight lid and repacked with another concentric steel container. The linear empty space of the container was filled with sand in the form of layer-by-layer up to outer container brim. The arrangement for carbonization was made under traces oxygen between the voids of material and reaction was executed at $800 \pm 5^{\circ} \mathrm{C}$ for $60 \mathrm{~min}$ in a furnace. Following, reaction mixture was cooled and excess $\mathrm{ZnCl}_{2}$ was subjected to leaching out by immersing in a hot solution of 1 $\mathrm{M} \mathrm{HCl}$ at $80 \pm 5^{\circ} \mathrm{C}$ for $24 \mathrm{~h}$ in the oven. The material was washed with hot water till the chloride was detached (tested by the silver nitrate method) and dried out at $105 \pm 5^{\circ} \mathrm{C}$ in a hot-air oven and filtered through $250-500 \mu \mathrm{m}$ size filter. The obtained material was designated as AC of J. curcas (ACJC) and stored in a desiccator at room temperature under dry place for a further purpose.

\section{Physicochemical Characterization of ACJC}

The physicochemical characteristics of the prepared ACJC were investigated using various analytical techniques including X-ray diffraction (XRD), Raman spectroscopy, Scanning electron microscope-energy dispersive X-ray (SEM-EDX), and Brunauer-Emmett-Teller (BET). The XRD analysis was carried out to understand the structural characteristics of the ACJC using X'Pert PRO X-ray Diffractometer (PANalytical, Spectris Technologies Pvt. Ltd., India) with $\mathrm{Cu} \mathrm{K} \alpha$ radiation source $(\lambda=1.541 \AA)$ in the $2 \theta$ range from $10^{\circ}$ to $70^{\circ}$ with a scanning rate $3^{\circ} / \mathrm{min}$. The average crystalline size of the prepared sample was calculated using Scherrer equation (Patterson, 1939). The Raman spectrum of ACJC was recorded using Renishaw's in Via Raman microscope (Renishaw India, Bengaluru) with spectrometer attachment. Green laser with $514 \mathrm{~nm}$ wavelength set in a low power mode $(0.5 \%$ of maximum power) was used to excite the sample. The surface micro-morphology and chemical configuration of ACJC were assessed using SEM (Quanta 200, ICON Analytical Equipment Pvt. Ltd., United States) attached EDX detector. The precise surface area of ACJC was determined using BET surface area analyzer (Micromeritics TriStar II, United States).

\section{Application of ACJC for Adsorption of ZEA}

\section{Experimental Plan}

The adsorption of ZEA (adsorbate) by ACJC (adsorbent) was studied with various parameters (contact time, concentration of ZEA and ACJC, and $\mathrm{pH}$ of media) at room temperature $\left(25 \pm 2^{\circ} \mathrm{C}\right)$. The ZEA stock was prepared in acetonitrile $(10 \mathrm{mg} / \mathrm{mL})$ and further test concentration of ZEA was made in buffer solutions (CBS and D-PBS). The CBS was used as media to carry out adsorption studies at $\mathrm{pH} 3,4,5$, and 6 while D-PBS was used as media for adsorption at $\mathrm{pH}$ of 7,8 , and 9.

\section{Adsorption Studies}

The impact of contact time (min) on adsorption of ZEA by ACJC was measured with different concentration of ZEA $(25,50,75$, and $100 \mu \mathrm{g} / \mathrm{mL})$ and $1 \mathrm{mg} / \mathrm{mL}$ of $\mathrm{ACJC}$ at $\mathrm{pH} 7$ for a period of $3 \mathrm{~h}$. A volume of $50 \mu \mathrm{L}$ sample solution was collected at an appropriate time interval and used for the quantification of ZEA. The time at which adsorption of ZEA was saturated defined as adsorption equilibrium time and used as a constant time period for further studies. To determine the influence of $\mathrm{pH}$ on adsorption of ZEA by ACJC, the experiment was executed at different $\mathrm{pH}(3,4,5,6,7,8$, and 9) with $1 \mathrm{mg} / \mathrm{mL}$ of ACJC and 
different concentration of ZEA $(25,50,75$, and $100 \mu \mathrm{g} / \mathrm{mL})$ at adsorption equilibrium time. The impact of altered concentration of ACJC $(0.5,1,1.5,2,2.5,3,3.5$, and $4 \mathrm{mg} / \mathrm{mL})$ on adsorption of ZEA $(100 \mu \mathrm{g} / \mathrm{mL})$ was studied at $\mathrm{pH} 7$ and adsorption equilibrium time. In all the experimental setups, the test samples were vortexed at $145 \mathrm{rpm}$ and at room temperature under dark throughout the experiment. At an appropriate time interval, the required test sample was collected and filtered by $0.22 \mu \mathrm{m}$ syringe filter and the filtrate was used for the quantification of ZEA employing HPLC. The ZEA test solution prepared in buffer solutions without ACJC was referred as a control throughout the experiment.

\section{Desorption Studies}

The stability of ZEA adsorption by ACJC was determined by changing the $\mathrm{pH}$ of media. The ZEA adsorption study was carried out at $\mathrm{pH} 7$ with 25, 50, 75, and $100 \mu \mathrm{g} / \mathrm{mL}$ of ZEA and $1 \mathrm{mg} / \mathrm{mL}$ of ACJC for a period of adsorption equilibrium time. Following, the adsorbent was removed from the test sample by centrifugation at $4000 \mathrm{rpm}$ and suspended at $\mathrm{pH} 3$ and vortexed for $30 \mathrm{~min}$ at $145 \mathrm{rpm}$ under dark. The supernatant of adsorption and desorption studies were used for the quantification of ZEA.

\section{Quantification of ZEA by HPLC}

The quantification of ZEA was carried out using HPLC (Shimadzu, Japan) attached with Luna C18 column, $5 \mu \mathrm{m}$ thickness, and length of $250 \mathrm{~mm} \times 4.6 \mathrm{~mm}$ (Phenomenex, United States) as per our previous reported methodology (Kalagatur et al., 2015). The quantity of ZEA adsorbed by ACJC was determined as the difference between the quantity of ZEA in control and supernatant of the test sample with ACJC. The amount of ZEA bound to the ACJC was determined by the following formula:

$$
q_{\mathrm{e}}=\left[\left(C_{0}-C_{\mathrm{e}}\right) V\right] / m
$$

where $q_{\mathrm{e}}$ was amount of ZEA adsorbed by specific quantity of ACJC $(\mu \mathrm{g} / \mathrm{mg}), C_{0}$ was initial amount of ZEA in supernatant of control $(\mu \mathrm{g} / \mathrm{mL}), C_{e}$ was amount of ZEA left over in supernatant of test sample at equilibrium time $(\mu \mathrm{g} / \mathrm{mL}), V$ was volume of experimental solution $(\mathrm{mL})$, and $m$ was quantity of ACJC (mg).

\section{Adsorption Isotherms}

The obtained data of adsorption studies were applied to optimize the design of adsorption by equilibrium isotherms of Freundlich and Langmuir models. The Langmuir model was founded on the hypothesis that adsorption was a category of chemical process and the adsorbed layer was measured as unimolecular. The linear form Langmuir model can be represented as follows:

$$
\frac{C_{\mathrm{e}}}{q_{\mathrm{e}}}=\frac{1}{q_{\mathrm{e}} b}+\frac{C_{\mathrm{e}}}{q_{0}}
$$

where $q_{0}$ signifies the adsorption capacity of ACJC ( $\left.\mu \mathrm{g} / \mathrm{mg}\right), q_{\mathrm{e}}$ was the quantity of ZEA adsorbed by ACJC at equilibrium time $(\mu \mathrm{g} / \mathrm{mg})$, and $b$ signifies the energy of adsorption $(\mathrm{mL} / \mathrm{mg})$.

The adsorption capacity $\left(q_{0}\right)$ and adsorption energy $(b)$ of ACJC were determined from slope and intercept of linear plots of $C_{\mathrm{e}} / q_{\mathrm{e}}$ versus $C_{\mathrm{e}}$. The goodness of fit was determined from the correlation coefficient of the fitted curve. The essential characteristics of the Langmuir isotherm can be conveyed by a dimensionless constant called equilibrium parameter $\left(R_{\mathrm{L}}\right)$, which signifies the type of isotherm. The $R_{\mathrm{L}}$ indicates that adsorption to be favorable $\left(0<R_{\mathrm{L}}<1\right)$, linear $\left(R_{\mathrm{L}}=1\right)$, irreversible $\left(R_{\mathrm{L}}=0\right)$, and unfavorable $\left(R_{\mathrm{L}}>1\right)$ (El-Sayed et al., 2014). The $R_{\mathrm{L}}$ was deducted using the following formula:

$$
R_{\mathrm{L}}=1 /\left(1+b C_{0}\right)
$$

The Freundlich isotherm model assumes that ratio of adsorbent adsorbed to the amount of adsorbate is a function of the solution. The empirical model was consistent with the characteristic of heterogeneous surfaces and an exponential distribution of active centers. Thus, the amount of adsorbent adsorbed $\left(q_{\mathrm{e}}\right)$ is correlated to the to the equilibrium concentration of adsorbate in solution $\left(C_{\mathrm{e}}\right)$. The heterogeneous sorption model of Freundlich can be represented as follows:

$$
q_{\mathrm{e}}=K_{\mathrm{F}} C_{\mathrm{e}}^{1 / \mathrm{n}}
$$

The $K_{\mathrm{F}}$ determines the favorability of the adsorption process. The linearized equation by taking logarithm both sides can be represented as follows:

$$
\ln q_{\mathrm{e}}=\ln K_{\mathrm{F}}+1 / n \ln C_{\mathrm{e}}
$$

\section{In Vitro Application of ACJC as an Antidote against ZEA-Induced Toxicity Design of Experiment}

In the final aim of the study, adsorption property of ACJC was utilized to establish ACJC as an antidote against ZEAinduced toxicity under in vitro studies. The antidote application of ACJC against ZEA-induced toxicity was assessed in neuro2a cells (neuroblastoma of Mus musculus) by determining the live and dead cells, intracellular reactive oxygen species (ROS), mitochondrial membrane potential $\left(\Delta \Psi_{\mathrm{M}}\right)$, and caspase3 activity. The neuro-2a cell line was attained from the National Centre for Cell Science (NCCS), Pune, India. The cells were grown in DMEM added with $10 \% \mathrm{FBS}, 50 \mathrm{mU} / \mathrm{mL}$ of penicillin, and $50 \mu \mathrm{g} / \mathrm{mL}$ of streptomycin under a moist environment of $5 \% \mathrm{CO}_{2}$ and $95 \%$ air at $37^{\circ} \mathrm{C}$. The cells were grown in $75 \mathrm{~cm}^{2}$ flasks, media were changed at an alternative days, and confluent cells were used for the experiment. The experiment was designed into four groups: Group I: Cells were exposed only with D-PBS (control). Group II: Cells were exposed with ZEA $(25 \mu \mathrm{g} / \mathrm{mL})$ in D-PBS. Group III: Cells were exposed to $1 \mathrm{mg} / \mathrm{mL}$ of ACJC in D-PBS. Group IV: ZEA $(25 \mu \mathrm{g} / \mathrm{mL})$ and ACJC $(1 \mathrm{mg} / \mathrm{mL})$ were blended in D-PBS and exposed to the cells.

\section{Live/Dead Cell Assay}

The live/dead dual staining assay was carried out using calcein AM and ethidium homodimer-1 fluorescent dyes as per instructions of the manufacturer (Haugland et al., 1994). Approximately, $5 \times 10^{4}$ cells were seeded in 12 -well plate and the cells were allowed to settle for $6 \mathrm{~h}$. The cells were exposed to ZEA, ACJC, and the combination of ZEA and ACJC as mentioned in the Section "Design of Experiment" and incubated for $6 \mathrm{~h}$. 
Following, cells were washed with D-PBS for twice and stained with $2 \mu \mathrm{M}$ of calcein $\mathrm{AM}$ and $4 \mu \mathrm{M}$ of ethidium homodimer-1 prepared in D-PBS for $15 \mathrm{~min}$. Subsequently, cells were washed with D-PBS for twice and images were captured under filters of green fluorescent protein (GFP) and red fluorescent protein (RFP) using an inverted fluorescence microscope (EVOS, Life Technologies, United States). The intensity of fluorescence was recorded at excitation and emission of 485 and $530 \mathrm{~nm}$ for calcein AM and 530 and $645 \mathrm{~nm}$ for ethidium homodimer-1 using multiplate reader (Synergy H1, BioTek, United States), respectively. The percentages of live and dead cells were calculated using the formula (Garcia-Recio et al., 2015):

$$
\begin{aligned}
& \text { Live cells }(\%)=\frac{F(530)_{\text {sam }}-F(530)_{\text {min }}}{F(530)_{\max }-F(530)_{\min }} \times 100 \\
& \text { Dead cells }(\%)=\frac{F(645)_{\text {sam }}-F(645)_{\min }}{F(645)_{\max }-F(645)_{\min }} \times 100
\end{aligned}
$$

where $F(530)_{\text {sam }}$ and $F(645)_{\text {sam }}$ were fluorescence of sample labeled with calcein AM and ethidium homodimer-1 at 530 and $645 \mathrm{~nm}$, respectively. $F(530)_{\text {min }}$ was fluorescence of sample at $530 \mathrm{~nm}$ labeled with ethidium homodimer-1 alone, where all cells were alive. $F(530)_{\max }$ was fluorescence of sample at $530 \mathrm{~nm}$ labeled with calcein AM alone, where all cells were alive. $F(645)_{\min }$ was fluorescence intensity of the sample at $645 \mathrm{~nm}$ labeled with calcein AM alone, where all cells were dead. $F(645)_{\max }$ was fluorescence intensity of the sample at $645 \mathrm{~nm}$ labeled with ethidium homodimer-1 alone, where all cells were dead.

\section{Determination of Intracellular ROS}

The estimation of intracellular ROS molecules of cells was carried out using DCFH-DA fluorescent probe (Venkataramana et al., 2014). Approximately, $5 \times 10^{4}$ cells were seeded in 12 -well cell culture plate and incubated for $6 \mathrm{~h}$ to attach the cells to the plate. Following, cells were exposed to different experimental groups as mentioned in the Section "Design of Experiment" and incubated for $6 \mathrm{~h}$. The cells were washed with D-PBS for twice and stained with $5 \mu \mathrm{M}$ of DCFH-DA for $5 \mathrm{~min}$. Subsequently, cells were washed with D-PBS for twice and fluorescent microscopic images of cells were captured under GFP filter using an inverted microscope (EVOS, Life Technologies, United States) and optical density was measured with the multiplate reader (Synergy H1, BioTek, United States) at excitation and emission of 495 and $550 \mathrm{~nm}$, respectively. The results were expressed in percentage of fluorescence released with respect to the control.

\section{Determination of Mitochondrial Membrane Potential $\left(\Delta \Psi_{M}\right)$}

The $\Delta \Psi_{\mathrm{M}}$ of the cell was determined by rhodamine 123 fluorescent probe (Venkataramana et al., 2014). Approximately, $5 \times 10^{4}$ cells were seeded in 12 -well cell culture plate and allowed to settle for $6 \mathrm{~h}$ and treated with differential experimental groups as mentioned in Section "Design of Experiment" and incubated for $6 \mathrm{~h}$. Following, cells were washed for twice with D-PBS and stained with $5 \mu \mathrm{M}$ of rhodamine 123 for $15 \mathrm{~min}$. Again, cells were subjected to washing for twice with D-PBS and images were captured under GFP filter using an inverted fluorescent microscope (EVOS, Life Technologies, United States) and optical density was monitored at $534 \mathrm{~nm}$ using a multiplate reader (Synergy H1, BioTek, United States). The results were expressed in percentage of $\Delta \Psi_{\mathrm{M}}$ with respect to the control.

\section{Analysis of Apoptosis by Caspase- 3 Kit}

The caspase-3 kit was used to estimate the caspase- 3 and apoptosis (Riss et al., 2016). Approximately, $5 \times 10^{4}$ cells were seeded in 12-well cell culture plate and allowed to settle for $6 \mathrm{~h}$ and treated with differential experimental groups as mentioned in the Section "Design of Experiment" and incubated for $6 \mathrm{~h}$. Following, the cells were washed with D-PBS for twice and treated with the caspase-3 fluorimetric kit as per technical bulletin of the manufacturer and optical density was recorded at an excitation and emission of 360 and $460 \mathrm{~nm}$, respectively. The caspase- 3 levels were calculated from a standard of the fluorescent molecule 7-amino-4-methyl coumarin (AMC) release. The results were expressed in percentage of caspase- 3 release with respect to the control.

\section{Statistical Analysis}

The experiments were undertaken individually for six times $(n=6)$ and results were expressed in mean \pm SD. The statistical analysis was executed by one-way ANOVA following Dunnett's test and $p$-value $<0.05$ was stated as statistically significant $\left({ }^{*} p<0.05,{ }^{* *} p<0.01\right.$, and $\left.{ }^{* * *} p<0.001\right)$.

\section{RESULTS AND DISCUSSION}

\section{Synthesis and Physicochemical Characterization of ACJC}

Since last decade, researchers around worldwide have been highly focused on to develop low-cost AC from the abundant and cheaply accessible natural resources. The plant sources are a highly suitable for synthesis of AC due to its high cellulose and hemicellulose content, and the cellulose and hemicellulose have exhibited a high potential sorption competence toward a variety of toxic compounds (Correa et al., 2017; Ooi et al., 2017). Henceforth, in the present study, cellulose- and hemicelluloserich seed shells of $J$. curcas were used as a raw material to synthesize of $\mathrm{AC}$ by $\mathrm{ZnCl}_{2}$ chemical activation method.

The crystalline phase of synthesized ACJC was identified from the XRD result (Figure 1). The diffraction patterns agree well with the standard JCPDS file (41-1487), which confirmed the formation of crystalline structures of the graphitic carbon. The obtained diffraction peaks are indexed to the corresponding peaks for (002), (100), and (101) crystal planes of graphitic carbon. The presence of a sharp peak around $26^{\circ}$ has confirmed the crystalline structure of ACJC which portrays the superior alignment of disordered graphitic carbon layers to form the crystalline turbostratic structure ( $\mathrm{Li}$ et al., 2007). The average crystallite size of ACJC was calculated from the FWHM value of the highly intense peak corresponding to the (002) crystal plane. It is found that the ACJC has an average crystallite size of $1.07 \mathrm{~nm}$. The peak splitting observed in the X-ray diffraction 


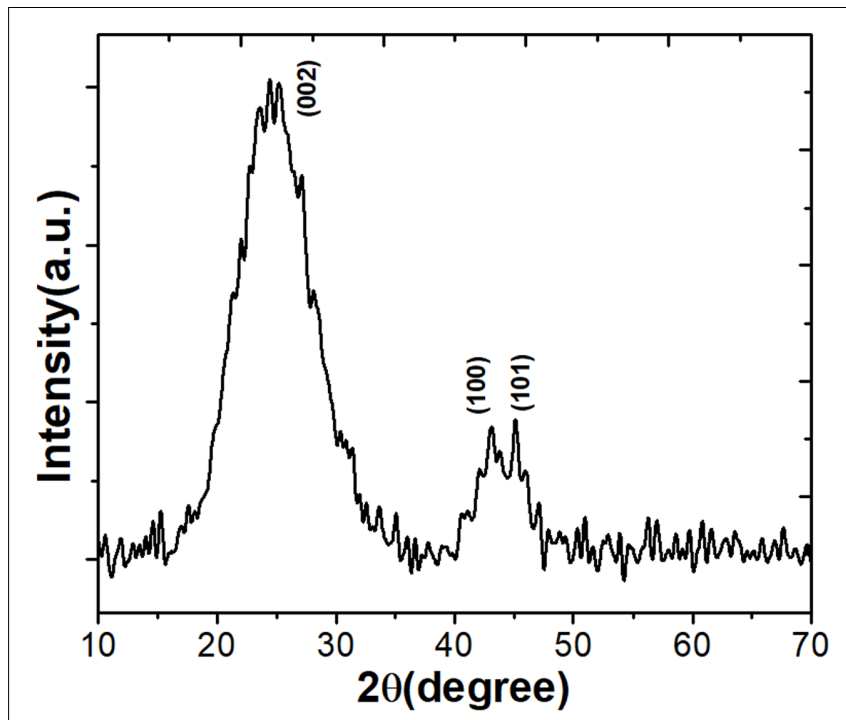

FIGURE 1 | The X-ray diffraction (XRD) pattern of the prepared activated carbon (AC) of J. curcas (ACJC).

peaks are due to the transition of carbon from a highly symmetric phase to a lower one. It also shows the presence of microporous wall structure of ACJC. The XRD results confirmed that ACJC has a better crystallographic structure as well-organized aromatic carbon that is more stable than amorphous-like carbon and these results were further evaluated by Raman spectroscopic analysis.

Figure 2 shows the Raman spectrum recorded by exciting the sample using a green laser with $514 \mathrm{~nm}$ excitation wavelength. The Raman spectrum of ACJC elucidates the chemical structure and crystalline nature of the prepared sample. The $514 \mathrm{~nm}$ selectively excites the $\pi$ state of $\mathrm{sp}^{2}$ hybridized carbon molecules. The obtained Raman peaks around 1303 and $1589 \mathrm{~cm}^{-1}$ are indexed to the $D$ band and $G$ band of the graphitic carbon particles, respectively. The $G$ band represents the peak corresponding to vibrational modes arises due to the stretching of bonds associated with the pairs of $\mathrm{sp}^{2}$ hybridized carbon atoms present either in carbon molecular chain or in aromatic ring. The E2g symmetry modes around $1589 \mathrm{~cm}^{-1}$ in the $\mathrm{G}$ band confirm the presence of highly crystalline and ordered nature of graphitic carbon in ACJC. Compared to the G band of graphite around $1575 \mathrm{~cm}^{-1}$, the higher value of peak at $1589 \mathrm{~cm}^{-1}$ for the $G$ band of ACJC sample is attributed to the $\mathrm{C}-\mathrm{C}$ bond bending in the sample due to the porous nature of the ACJC. The D band observed around $1303 \mathrm{~cm}^{-1}$ corresponds to the A1g mode called as lattice breathing mode. The presence A1g breathing mode reveals the structural disorder in the sample. Moreover, the peak corresponding to the D3 band absent in the ACJC, which confirms that the amorphous phase of carbon between graphitic layers is absent in the ACJC sample. Hence, it confirms that the ACJC sample is highly crystalline nature (Lazzarini et al., 2016).

The SEM analysis was undertaken to determine the surface morphology of the synthesized ACJC and micrographs were recorded at different magnifications $(500 \times$ and $1000 \times)$ as shown in Figure 3A. The obtained images revealed the honeycomb

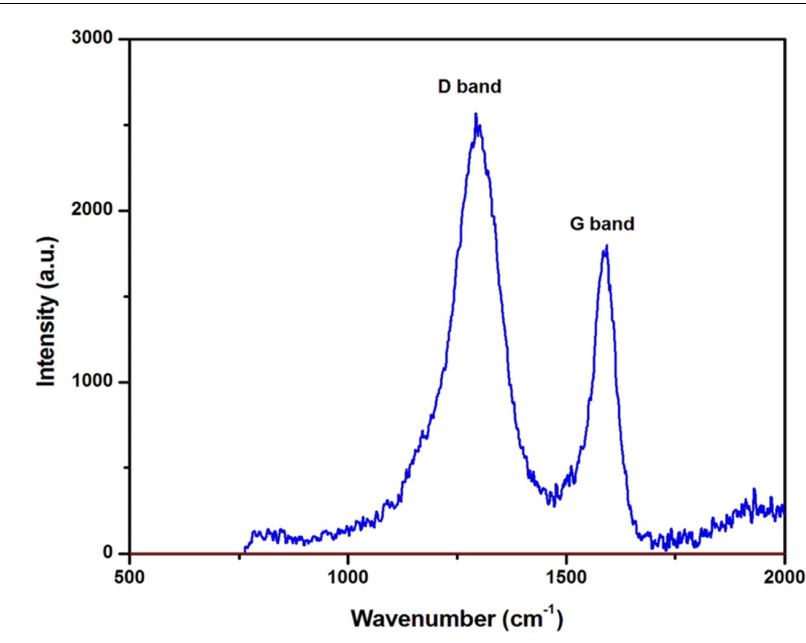

FIGURE 2 | Raman spectroscopy of AC of J. curcas (ACJC) was captured at an excitation wavelength of $514 \mathrm{~nm}$ using a green laser.

void structure analogous to the turbostratic morphology of the carbon particles, and this result is in perfect agreement with the structural data obtained from XRD analysis. The $\mathrm{ZnCl}_{2}$ chemical activation method has established new microporous as well as widened existing microporous by increasing the volume and surface area of the microporous, and these pores were formed because of $\mathrm{ZnCl}_{2}$ evaporation during carbonization. These large volumes of microporous developed by $\mathrm{ZnCl}_{2}$ were helpful in engulfing the contaminants. The volume and surface area of microporous depends on the structure of precursor applied for the carbonization purpose.

The elemental analysis of ACJC was carried out using EDX technique and results suggest that the seed shells of $J$. curcas contain a good amount of carbon. The carbonization of seed shells of $J$. curcas by $\mathrm{ZnCl}_{2}$ chemical activation has increased the carbon content and indicated successful carbonization of seed shells of $J$. curcas results in the formation of ACJC. Figure 3B elucidated the presence of carbon (C) and oxygen (O) in ACJC and wt. \% of $\mathrm{C}$ and $\mathrm{O}$ were 93.36 and 6.64, respectively. A small amount of oxygen is present in the ACJC due to the oxidation of carbon during the heat treatment process.

The adsorption capacity of AC depends on volume, size, and specific surface area of the pore (Dizbay-Onat et al., 2017). The specific surface of ACJC was assessed from adsorption experiments on the basis of the BET method, and the micropore volume $(V)$ was evaluated by calculating the adsorbate volume. The $t$-curve was analyzed to measure the thickness of the adsorbed film (Senniappan et al., 2016). The BET analysis was helpful in establishing the relationship between surface area and material properties of samples and the effect of activation temperature, activator, impregnation ratio in the formation of pore formation (Ab Ghani et al., 2017). In the present study, ACJC with the greater surface area was obtained by $\mathrm{ZnCl}_{2}$ chemical activation at a higher temperature (Liu et al., 2016). The porous structure of ACJC is due to the "swelling effect" caused by the electrolytic action of $\mathrm{ZnCl}_{2}$ which breaks the 

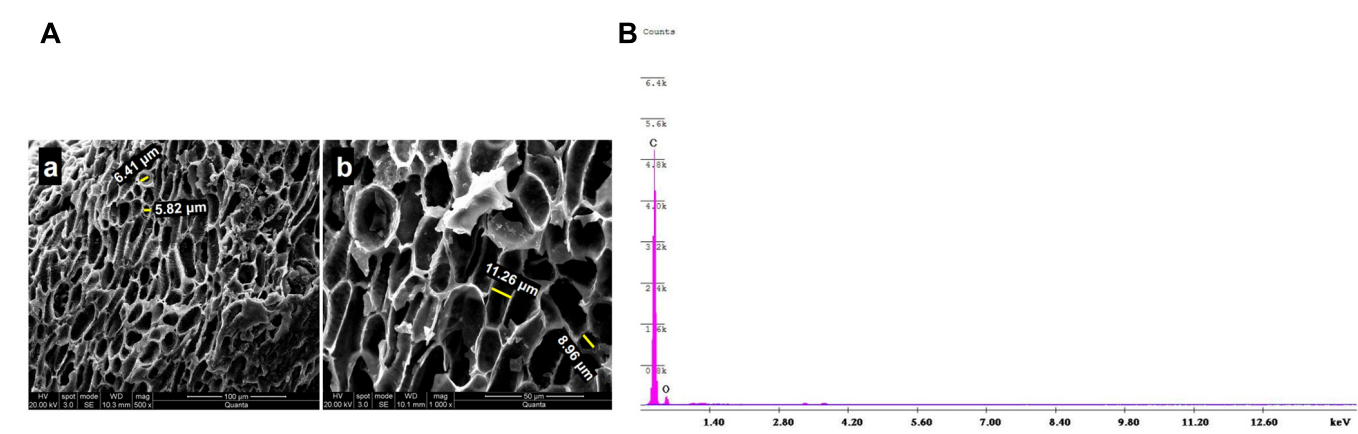

FIGURE 3 | (A) SEM images of AC of J. curcas (ACJC) were captured at a different magnification of (a) $500 \times$ and (b) $1000 \times$. (B) Elemental composition of AC of J. curcas (ACJC) was determined by EDX spectrum.

lateral bonds in the cellulose molecules and increases the pore density in the molecular structure of seed shells of $J$. curcas. Therefore, microporosity and surface area of ACJC has increased (Liu et al., 2016). The $\mathrm{S}_{\mathrm{BET}}$, micropore area, and average pore diameter of ACJC were observed as $822.78\left(\mathrm{~m}^{2} / \mathrm{g}\right), 255.36$ $\left(\mathrm{m}^{2} / \mathrm{g}\right)$, and $8.5980(\AA)$, respectively (Figures 4A,B). In support of our result, IUPAC has also concluded from $S_{B E T}$ results that the occurrence of type I isotherm with high pressure at horizontal plateau could result in the development of narrow pore size scattered microporous material. The Fractal dimension, which is a measure of the roughness of a surface of ACJC, was estimated by applying the Frenkel-Halsey-Hill (FHH) equation to $\mathrm{N}_{2}$ adsorption isotherms. The results showed that the change in Fractal dimension was insignificant and the complete development of pores on the surface of ACJC was due to the activation of $\mathrm{ZnCl}_{2}$ (Carrott and Carrott, 2007).

\section{Adsorption of ZEA by ACJC}

The contact time involved between ACJC (adsorbent) and ZEA (adsorbate) is one of the key factors that considerably influence the adsorption process (El-Sayed et al., 2014). The effect of contact time on the adsorption of ZEA by ACJC was investigated with a different initial concentration of ZEA $(25,50,75$, and $100 \mu \mathrm{g} / \mathrm{mL}$ ) and $1 \mathrm{mg} / \mathrm{mL}$ of ACJC at $\mathrm{pH} 7$. Based on the kinetic investigations, the plot of ZEA adsorption by ACJC $(\mu \mathrm{g} / \mathrm{mg})$ versus contact time (min) was presented in Figure 5A. The results showed the rapid adsorption of ZEA by ACJC for initial 15 min of contact time. Following the contact time, adsorption of ZEA was slow down until equilibrium was obtained and the time taken to obtain adsorption equilibrium time was $120 \mathrm{~min}$. A quantity of $21.27 \pm 1.26,21.56 \pm 0.48,22.21 \pm 0.64$, and $23.02 \pm 0.82 \mu \mathrm{g}$ of ZEA was adsorbed by $1 \mathrm{mg}$ of ACJC at equilibrium time for the different initial concentration of $25,50,75$, and $100 \mu \mathrm{g} / \mathrm{mL}$ of ZEA, respectively. The reason behind the adsorption of ZEA by ACJC may be the involvement of strong attraction forces between the positive sites of cationic ZEA and anionic sites of ACJC (Lemke et al., 1998). The study has established ZEA adsorption capability of ACJC over short period of time and it could be effective for decontamination of ZEA.

The effect of different concentration of ACJC $(0.5-4 \mathrm{mg} / \mathrm{mL})$ on the adsorption of ZEA $(100 \mu \mathrm{g} / \mathrm{mL})$ was studied at $\mathrm{pH} 7$.
The concentration of ZEA adsorption was enhanced with an increase in the dose of ACJC. The kinetic model of ZEA adsorption $(\mu \mathrm{g} / \mathrm{mL})$ versus concentration of ACJC $(\mathrm{mg} / \mathrm{mL})$ for a period of adsorption equilibrium time $(120 \mathrm{~min})$ was depicted in Figure 5B. A quantity of $0.5,1,1.5,2,2.5,3,3.5$, and $4 \mathrm{mg} / \mathrm{mL}$ of ACJC has adsorbed 12.26 $\pm 0.20,23.02 \pm 0.82,34.61 \pm 0.52$, $46.29 \pm 0.95,53.72 \pm 0.67,66.58 \pm 0.86,71.15 \pm 1.46$, and $86.92 \pm 1.39 \mu \mathrm{g}$ of ZEA with initial concentration of $100 \mu \mathrm{g} / \mathrm{mL}$ of ZEA, respectively. The quantity of ZEA adsorbed was increased with increasing the dose of ACJC and results showed that it was in the mode of dose-dependent. The reason for the increase in adsorption of ZEA was due to the availability of more number of surface adsorption sites resulting from the increased concentration of ACJC (Sayğılı and Güzel, 2016). The study concluded that the concentration of ACJC was a determinant factor for adsorption of ZEA.

The effect of $\mathrm{pH}$ on adsorption of ZEA by ACJC was studied by varying the $\mathrm{pH}(3,4,5,6,7,8$, and 9) of media with different concentration of ZEA $(25,50,75$, and $100 \mu \mathrm{g} / \mathrm{mL})$ and $1 \mathrm{mg} / \mathrm{mL}$ of ACJC. The kinetic model of ZEA adsorption by ACJC $(\mu \mathrm{g} / \mathrm{mg})$ versus $\mathrm{pH}$ of media at adsorption equilibrium time $(120 \mathrm{~min})$ was showed in the Figure 5C. The results showed that adsorption of ZEA was noticeably not altered with a change in $\mathrm{pH}$ of media. Our result was in accordance with the previous report of Avantaggiato et al. (2014). The pH of media alters the surface charge of adsorbent and the degree of ionization of adsorbate, and it can alter the shift in kinetics and equilibrium of the adsorption process, and it is highly significant during the electrostatic interactions. Generally, the charge of the adsorbate depends on its $\mathrm{pK}_{\mathrm{a}}$ value and the adsorbate exists mainly in protonated form at $\mathrm{pH}<\mathrm{pK}_{\mathrm{a}}$ and in deprotonated form at $\mathrm{pH}>\mathrm{pK}_{\mathrm{a}}$. Therefore, the effect of $\mathrm{pH}$ on adsorption of ZEA by ACJC was dependents on the degree of ionization molecules. However, ZEA has $\mathrm{pK}_{\mathrm{a}}$ value of 7.6 with diphenolic compound structure and some amount of phenolate anion present in water at $\mathrm{pH} 7$ and the degree of ionization of ZEA was negligible. Therefore, the effect of $\mathrm{pH}$ on ZEA adsorption was negligible (Avantaggiato et al., 2014).

Desorption studies of different concentration of ACJC were undertaken with changing the $\mathrm{pH}$ of the media. The ZEA adsorption study was carried out at $\mathrm{pH} 7$ with $100 \mu \mathrm{g} / \mathrm{mL}$ of 

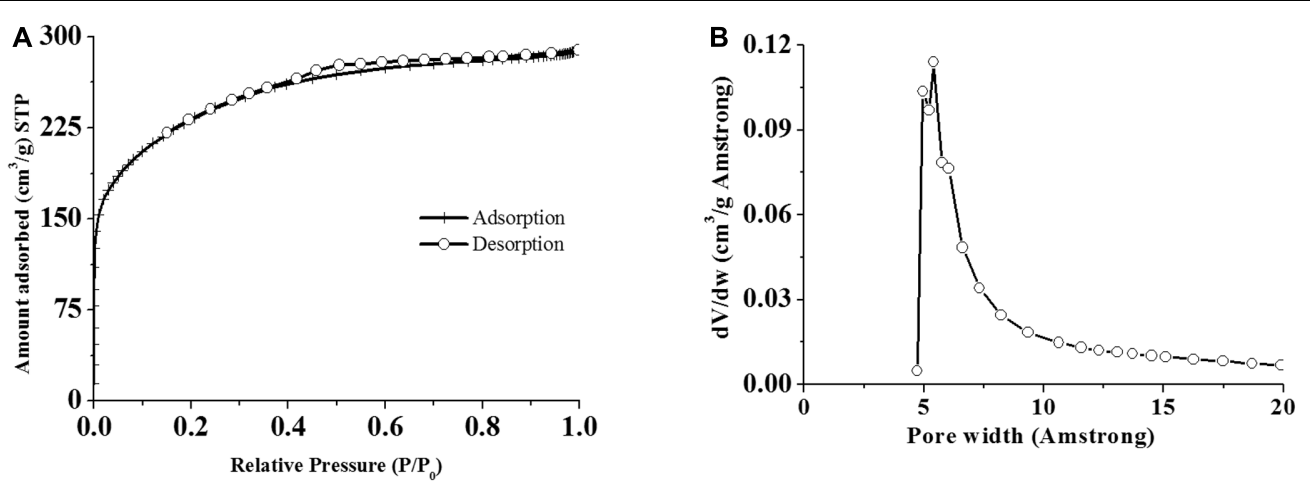

FIGURE 4 | Determination of (A) specific surface area and (B) pore width of AC of J. curcas (ACJC) by BET analysis.
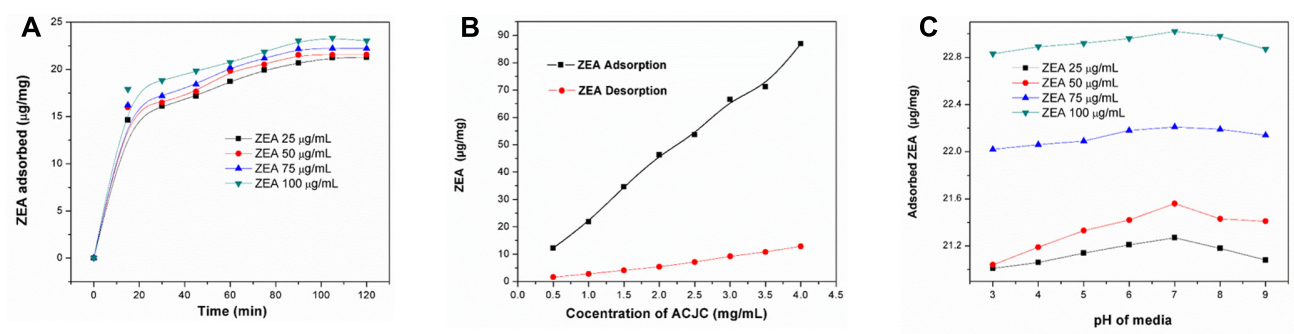

FIGURE 5 | The adsorption of zearalenone (ZEA) by AC of J. curcas (ACJC) under various parameters (contact time, concentration of ZEA and ACJC, and pH of media). (A) Effect of contact time ( $\mathrm{min}$ ) on adsorption of the different initial concentration of ZEA (25, 50, 75, and $100 \mu \mathrm{g} / \mathrm{mL}$ ) by $1 \mathrm{mg} / \mathrm{mL}$ of ACJC. (B) Adsorption and desorption curve of ZEA for different concentration of ACJC $(0.5,1,1.5,2,2.5,3,3.5$, and $4 \mathrm{mg} / \mathrm{mL})$ at pH 7 and 3 , respectively. The adsorption of ZEA by ACJC was carried out at $\mathrm{pH} 7$ with $100 \mu \mathrm{g} / \mathrm{mL}$ of ZEA for adsorption equilibrium time. Desorption of adsorbed ZEA of different concentration of ACJC was studied at $\mathrm{pH}$ 3. (C) Effect of different $\mathrm{pH}(3,4,5,6,7,8$, and 9) on adsorption of ZEA (100 $\mu \mathrm{g} / \mathrm{mL})$ by $1 \mathrm{mg} / \mathrm{mL}$ of $\mathrm{ACJC}$ at adsorption equilibrium time of $120 \mathrm{~min}$.

ZEA and different concentration $(0.5,1,1.5,2,2.5,3,3.5$ and $4 \mathrm{mg} / \mathrm{mL}$ ) of ACJC for a period of adsorption equilibrium time and desorption studies were executed for period $30 \mathrm{~min}$ in the media of $\mathrm{pH}$ 3. The amount of ZEA desorbed from adsorbed amount of ZEA was observed as $1.59 \pm 0.02,2.77 \pm 0.14$, $4.08 \pm 0.31,5.38 \pm 0.24,7.06 \pm 0.71,9.24 \pm 0.59,10.79 \pm 0.64$, and $12.85 \pm 0.72 \mu \mathrm{g} / \mathrm{mL}$ for $0.5,1,1.5,2,2.5,3,3.5$ and $4 \mathrm{mg} / \mathrm{mL}$ of ACJC, respectively (Figure 5A). The results showed that low amount of ZEA was desorbed due to change in the $\mathrm{pH}$ of media and suggested that adsorption of ZEA by ACJC was stable with a change in $\mathrm{pH}$ of media.

The adsorption isotherms were deducted by plotting the quantity of ZEA adsorbed per unit of mass of ACJC $\left(q_{\mathrm{e}}\right)$ against the quantity of ZEA present in the external phase $\left(C_{\mathrm{e}}\right)$ under an equilibrium condition. The obtained data were analyzed by trial version of OriginPro 8.5 software program to fit the isotherm models of Langmuir and Freundlich by the equations (2) and (5), respectively (El-Sayed et al., 2014). The Langmuir model delivered well appropriate correlations for isotherm adsorption plots. The quantity of ZEA adsorbed per unit mass of ACJC was increased gradually by increasing the dose of ACJC. The isotherms presented an exponential graph and a typical Langmuir shape (Figure 6A). The isotherm provided a good fit line to experimental adsorption data with small variance and correlation coefficient $\left(R^{2}\right)$ of 0.9989 . The separation factor or equilibrium parameter $\left(R_{\mathrm{L}}\right)$ of Langmuir isotherm model was obtained from Eq. 3 to evaluate the favorability of ZEA adsorption by ACJC. The $R_{\mathrm{L}}$ values were observed in between 0.0116 and 0.0451 and it suggested that adsorption of ZEA by ACJC was favorable (ElSayed et al., 2014). The energy of adsorption (b) was observed as a $0.8460 \mathrm{~mL} / \mathrm{mg}$ and the maximum ZEA adsorption capacity of ACJC was $23.14 \mu \mathrm{g} / \mathrm{mg}$. The Freundlich isotherm model was constructed with $\ln q_{\mathrm{e}}$ versus $\ln C_{\mathrm{e}}$ following equation (5) (Figure 6B). The obtained correlation coefficient of 0.7049 suggested a high degree variance and model was not fitted (ElSayed et al., 2014). The study concluded that adsorption of ZEA by ACJC was well fitted with Langmuir isotherm model rather than Freundlich, and these results also demonstrated the monolayer sorption of ZEA by homogeneous sites of ACJC (El-Sayed et al., 2014).

The results of the study concluded that ACJC as an efficient decontaminating agent for ZEA. Further investigation should be undertaken to propose a detailed binding mechanism of ZEA with ACJC. Also, regeneration studies should need to carry in detail to recover the adsorbent. So that it will enhance the economic feasibility of the decontamination process. Furthermore, a variety of mycotoxins will be encountered in food and feed matrices, and therefore, the competitive adsorption potential of ACJC should need to be assessed with multicomponent mycotoxins. 

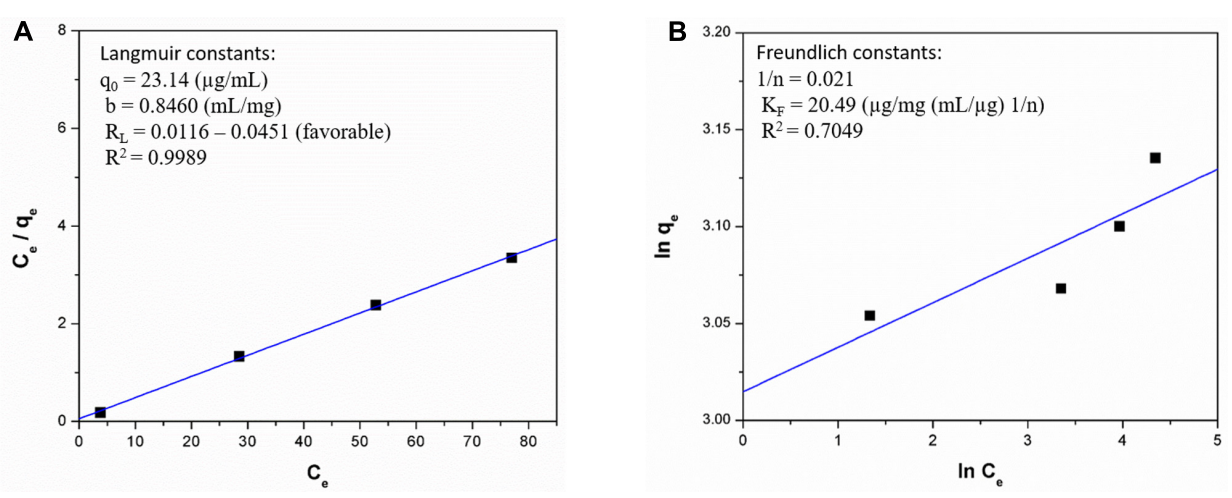

FIGURE 6 | (A) Langmuir and (B) Freundlich isotherm models for adsorption of zearalenone (ZEA) by AC of J. curcas (ACJC).

\section{In Vitro Analysis of ACJC as an Antidote against ZEA-Induced Toxicity}

In the therapeutic field, $\mathrm{AC}$ has found a diversity of application and used as an antidote to trap the swallowed chemicals, toxins, and overdose drugs in the gut and block their entry into the bloodstream. Therefore, the present study was lastly focused on to evaluate the adsorption feature of ACJC as an antidote against ZEA-induced cytotoxicity under in vitro studies. Many studies have proved the cytotoxicity of ZEA and reported that ZEA induces the toxicity by damaging the cellular membrane, generating intracellular ROS molecules, depleting the mitochondrial membrane potential $\left(\Delta \Psi_{\mathrm{M}}\right)$, and the apoptosis process (Venkataramana et al., 2014). The antidote action of ACJC against ZEA-induced toxicity was checked by assessing the cell membrane damage, generation of ROS molecules, mitochondrial membrane potential, and apoptosis.

The live/dead cell assay is a dual staining technique comprising of calcein AM and ethidium homodimer. The calcein $\mathrm{AM}$ is cell-permeant dye and in the live cells, calcein AM converted to a green-fluorescent calcein after acetoxymethyl ester hydrolysis by intracellular esterases, and therefore, live cells appear in green under GFP filter, while ethidium homodimer crosses the damaged cell membrane and binds to the nucleus of the cell and emits bright red fluorescence in dead cells under RFP filter (Haugland et al., 1994). In present study, $8.69 \pm 3.30 \%$ of live cells (green fluorescent cells) were noticed in ZEA treated cells and the percentage of dead cells (red fluorescent cells) were significantly $(p<0.05)$ high in ZEA treated cells compared to control cells and the results evidenced that ZEA-induced the cell death by damaging the cellular membrane (Figures 7A,B). On the other hand, cells exposed with ACJC were presented $95.46 \pm 2.39 \%(p<0.05)$ of live cells and results showed the non-toxicity of ACJC. The cells exposed together with ACJC and ZEA were exhibited $90.28 \pm 5.44 \%(p<0.05)$ of live cells and results indicated that ACJC has decreased the cytotoxicity of ZEA by lowering the availability of ZEA in media through adsorption.

The antidote action of ACJC on ZEA-induced toxicity in neuro-2a cells was also assessed by determining the intracellular ROS molecules by DCFH-DA probe. The DCFH-DA is a regularly used quantitative method to determine the oxidative

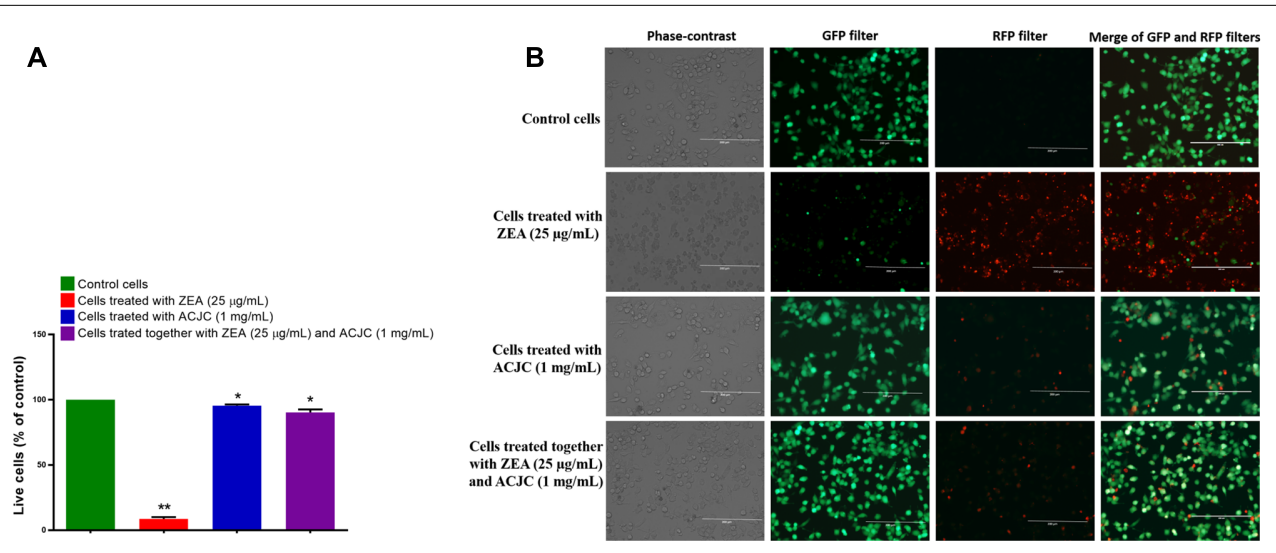

FIGURE 7 | Adsorption property of AC of J. curcas (ACJC) was utilized to establish as an antidote against zearalenone (ZEA)-induced toxicity under in vitro studies. (A) Determination of antidote action of ACJC on ZEA-induced toxicity in neuro-2a cells by live/dead cell assay. $\left({ }^{*} p<0.05,{ }^{* *} p<0.01\right.$, and $\left.{ }^{* * *} p<0.001\right)$.

(B) Phase-contrast and fluorescent microscopic images of control cells, ZEA exposed cells, ACJC exposed cells, and cells exposed together with ZEA and ACJC at a magnification of $400 \times$. 

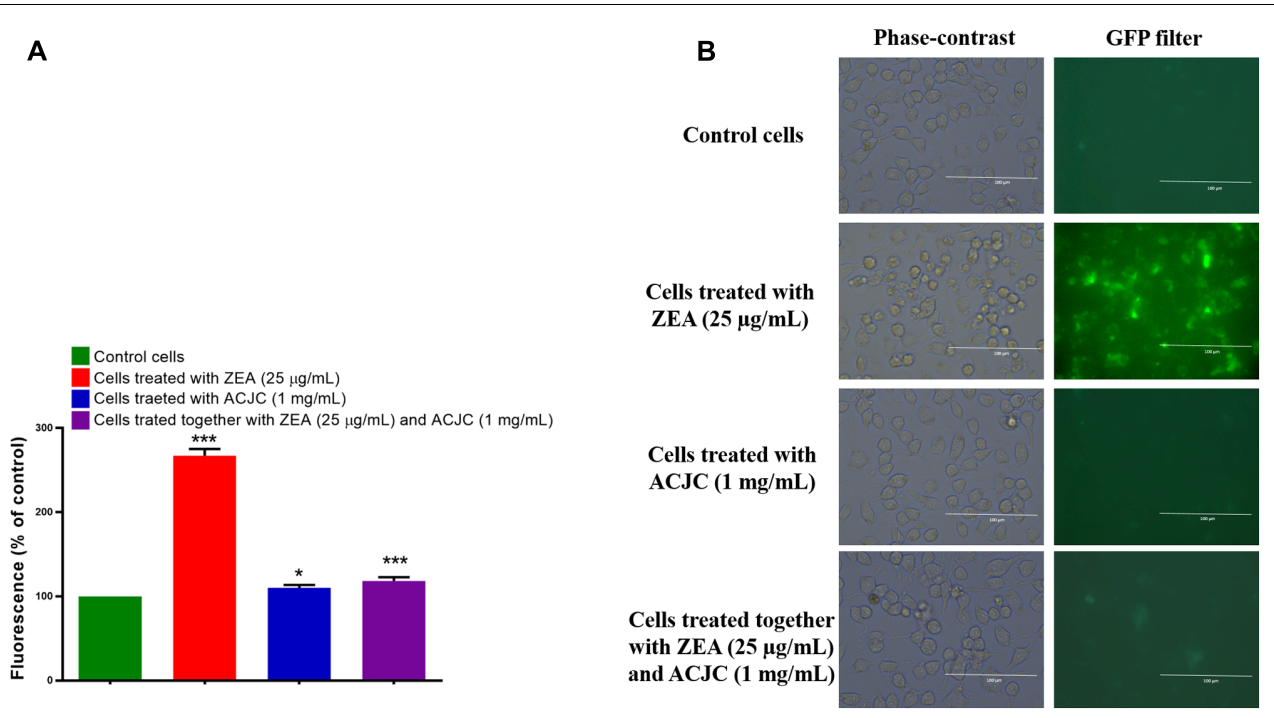

FIGURE 8 | (A) Determination of antidote action of AC of J. curcas (ACJC) against zearalenone (ZEA)-induced toxicity in neuro-2a cells by estimating the intracellular ROS molecules. $\left({ }^{*} p<0.05,{ }^{* *} p<0.01\right.$, and $\left.{ }^{* * *} p<0.001\right)$. (B) Phase-contrast and fluorescent microscopic images of control cells, ZEA treated cells, ACJC treated cells, and cells treated together with ZEA and ACJC at a magnification of $400 \times$.
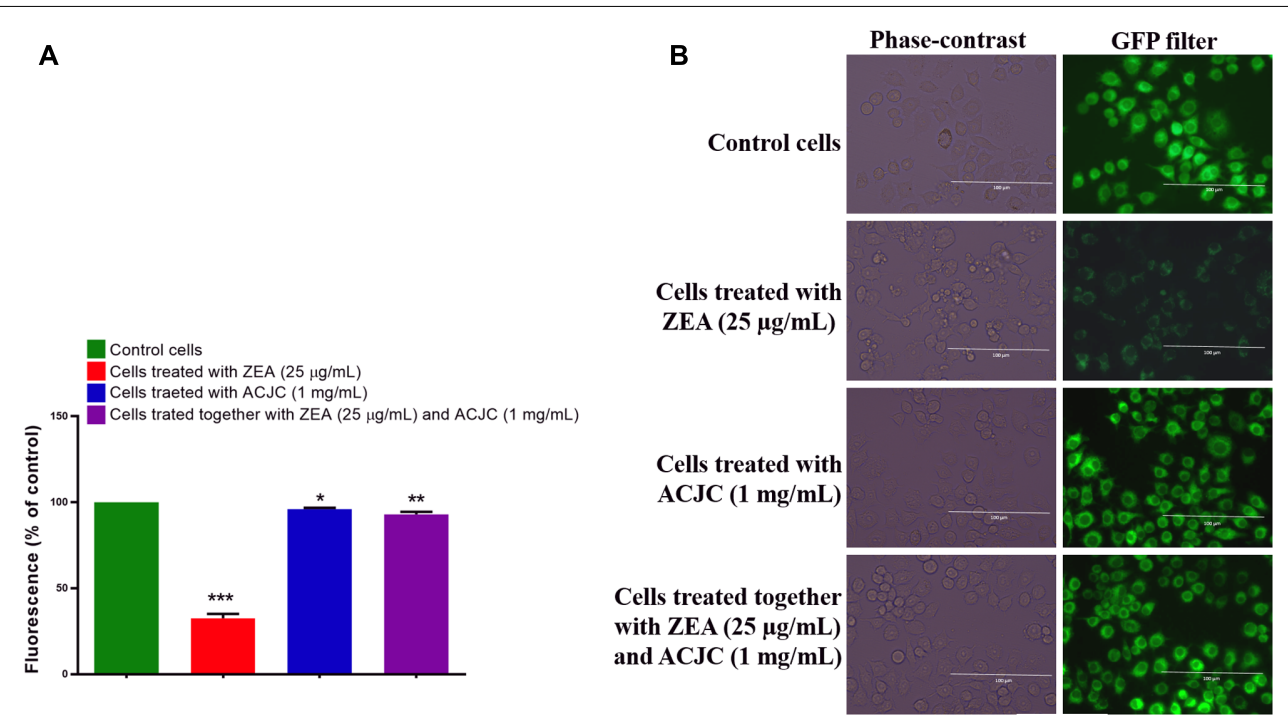

FIGURE 9 | (A) Establishment of AC of $J$. curcas (ACJC) as an antidote against zearalenone (ZEA)-induced toxicity in neuro-2a cells by assessing the mitochondrial membrane potential $\left(\Delta \Psi_{\mathrm{M}}\right)$. $\left({ }^{*} p<0.05,{ }^{* *} p<0.01\right.$, and $\left.{ }^{* * *} p<0.001\right)$. (B) Phase-contrast and fluorescent microscopic images of control cells, ZEA treated cells, ACJC treated cells, and cells treated together with ZEA and ACJC at a magnification of $400 \times$.

species. The DCFH-DA is deacetylated to the non-fluorescent compound by cellular esterases and further oxidize to $2^{\prime}, 7^{\prime}$ dichlorofluorescein (DCF) fluorescent molecules by intracellular ROS (Kumar et al., 2016; Sellamani et al., 2016). In the present study, the percentage of intracellular ROS $(267.24 \pm 19.46 \%)$ was high in ZEA treated cells compared to control $(p<0.05)$. Another hand, percentage of intracellular ROS molecules was not much affected in ACJC treated cells $(110.23 \pm 8.06)$ and these results were in line with live/dead cells assay and confirmed the non-toxicity of ACJC (Figures $\mathbf{8 A}, \mathbf{B}$ ). The results suggested that ZEA induces the cytotoxicity by oxidative stress through the generation of intracellular ROS molecules (Venkataramana et al., 2014). When cells exposed to a combination of ZEA and ACJC, the percentage of intracellular ROS molecules $(118.37 \pm 10.79 \%)$ was relatively less and not affected $(p<0.05)$. The reason is that ACJC has lowered the availability of ZEA in media by adsorption, and therefore, the level of intracellular ROS molecules was not affected by ZEA.

The antidote action of ACJC on ZEA-induced toxicity in neuro-2a cells was assessed by determining $\Delta \Psi_{\mathrm{M}}$ using probe 


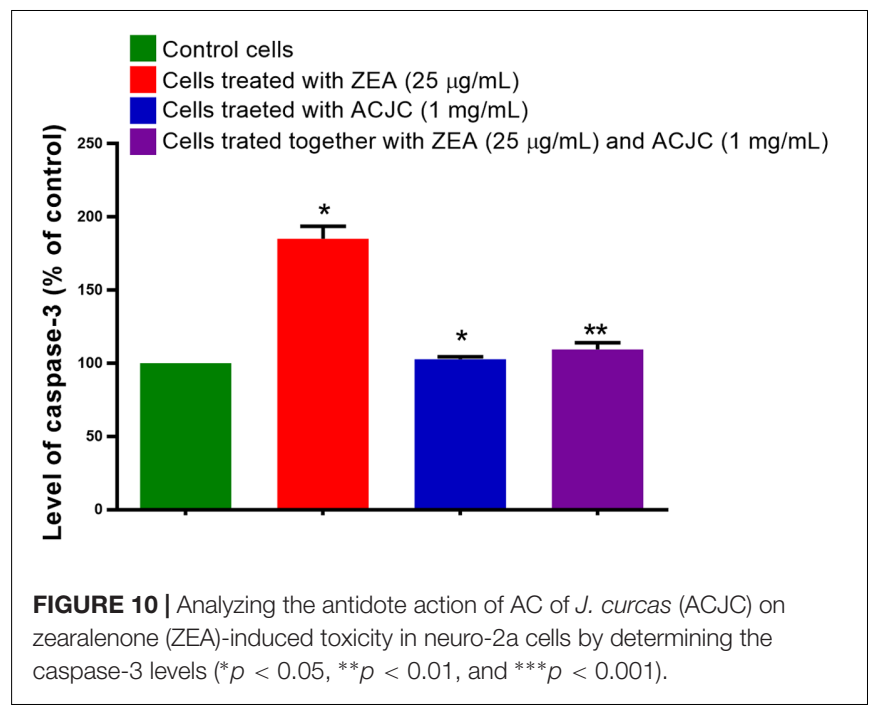

rhodamine 123 . The rhodamine 123 is cell permeable, cationic probe, and emits green fluorescence by the sequestered action of metabolically active mitochondria and measured as an indicator for $\Delta \Psi_{M}$ of the cell. The depletion in $\Delta \Psi_{M}$ of cell ceases the synthesis of adenosine triphosphate (ATP) molecules and activates the apoptosis process (Scaduto and Grotyohann, 1999). In the present study, $\Delta \Psi_{M}$ of cells was significantly $(p<0.05)$ depleted to $32.53 \pm 6.17 \%$ on exposure of ZEA (Figures 9A,B) and another hand, $\Delta \Psi_{M}$ was noticeably not affected by the treatment of ACJC $(96.01 \pm 1.85)$ compared to control $(p<0.05)$. Also, cells treated together with ZEA and ACJC was noticeably $(p<0.05)$ not exhibited depletion in $\Delta \Psi_{\mathrm{M}}(92.90 \pm 3.66)$. The results concluded that ACJC has adsorbed the ZEA and lower availability of ZEA in media and therefore, ZEA has failed to deplete the levels of $\Delta \Psi_{M}$ of the cell.

The apoptosis is the common way to induce the death of the cells by a variety of toxic compounds (Venkataramana et al., 2014). In the present study, antidote action of ACJC on ZEA-induced toxicity was determined by measuring the levels of caspase 3 using caspase- 3 detection kit following the instructions of the manufacturer. The caspase 3 is an associate of the cysteine-aspartic acid protease family and its successive activation plays a principal role in the accomplishment of cellular apoptosis. The caspase 3 hydrolysis the acetyl Asp-Glu-ValAsp 7-amido-4-methyl coumarin (Ac-DEVD-AMC) and releases the fluorescent AMC. The concentration of AMC released is directly proportional to the level of caspase 3 and apoptosis (Riss et al., 2016). The concentration of the AMC released was determined from the calibration curve of AMC standards. In the present study, the level of caspase 3 was elevated to $186.53 \pm 12.66 \%$ on the treatment of ZEA compared to control $(p<0.05)$ and it concluded that ZEA induces the death of cells by apoptosis (Figure 10). While cells exposed with ACJC have noticeably $(p<0.05)$ not presented the elevated levels of caspase$3(102.77 \pm 3.31)$. The cells exposed to a combination of ZEA and ACJC was also noticeably $(p<0.05)$ not exhibited the elevated levels of caspase $3(109.38 \pm 5.93)$ and this is due to lower availability of ZEA in media by means of adsorption of ZEA by ACJC.

All the above studies collectively concluded that ACJC has established as an antidote against ZEA-induced cytotoxicity. Furthermore, in vivo studies are required to evaluate the application of ACJC as an antidote against ZEA-induced toxicity. However, in support of our study Abdel-Wahhab et al. (2015) has assessed the antidote action of AC on DON-induced cytotoxicity and genotoxicity in rat and concluded that AC could be better antidotes to treat DONinduced toxicity. The JECFA also evaluated the toxicity of AC prepared by the $\mathrm{ZnCl}_{2}$ chemical method and recommended as food and feed additive to decontaminate a variety of toxic compounds (JECFA, 2010). Thus, the study concluded ACJC could be used as decontaminating and antidote against the ZEA-induced toxicity and the comprehensive conclusion of the study was presented in graphical design in Figure 11.

\section{CONCLUSION}

We have synthesized the AC from seed shells of J. curcas by using $\mathrm{ZnCl}_{2}$ chemical activation method. The physicochemical characteristics of the ACJC were characterized by using various

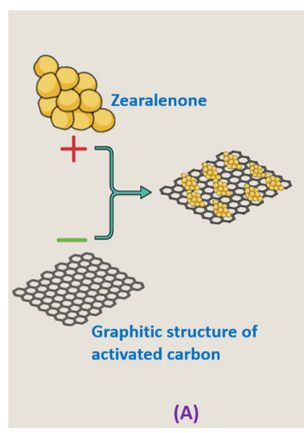

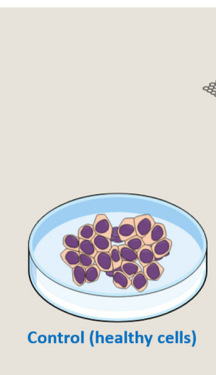

(A)

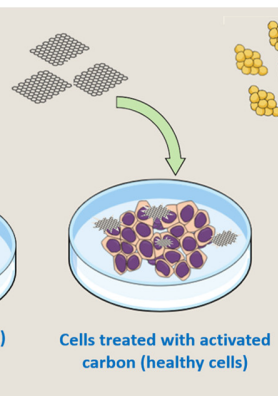

(B)

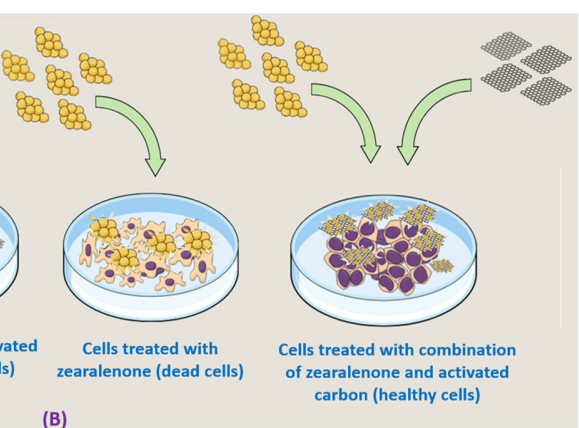

B) antidote action of ACJC against ZEA-induced toxicity

FIGURE 11 | under in vitro. 
analytical technique including XRD, Raman spectroscopy, SEMEDX, and BET surface analysis. The XRD spectrum indicated that raw seed shells of J. Curcas were successfully carbonized into crystalline AC. The formation of the graphitic phase of ACJC was confirmed from the results obtained from Raman spectroscopy analysis. The SEM images depicted that the ACJC has exhibited a large surface area due to its porous structure and morphology and the same has been confirmed from the BET results. Moreover, the presence of carbon and oxygen in the prepared ACJC samples were confirmed by the EDX analysis. The adsorption of ZEA by ACJC was studied with various parameters (contact time, a dose of ZEA and ACJC, and $\mathrm{pH}$ of the media). The ACJC has adsorbed the ZEA over a short period of time and adsorption of ZEA was noticed up to the setting up of adsorption equilibrium time. The dose of ACJC has effectively determined the adsorption of ZEA and showed that adsorption was dose-dependent. The different $\mathrm{pH}$ of the media was not much influenced by the adsorption of ZEA by ACJC. The desorption of ZEA was studied by changing the $\mathrm{pH}$ of the media and little amount of ZEA was desorbed due to change in $\mathrm{pH}$ of the media and results suggested that adsorption of ZEA by ACJC was stable. The results of adsorption studies were well fitted with Langmuir adsorption isotherm model and these results evidenced the homogeneous adsorption of ZEA by ACJC. The maximum adsorption of ZEA by ACJC was determined as $23.14 \mu \mathrm{g} / \mathrm{mg}$. The study concluded that ACJC was efficient for the decontamination of ZEA. The therapeutic application of ACJC against ZEA-induced toxicity was studied under in vitro in neuro-2a cells. The results suggested ACJC has successfully protected the cells from ZEA-induced cytotoxicity by lowering

\section{REFERENCES}

Ab Ghani, Z., Yusoff, M. S., Zaman, N. Q., Zamri, M. F. M. A., and Andas, J. (2017). Optimization of preparation conditions for activated carbon from banana pseudo-stem using response surface methodology on removal of color and COD from landfill leachate. Waste Manag. 62, 177-187. doi: 10.1016/j.wasman. 2017.02.026

Abdel-Wahhab, M. A., El-Kady, A. A., Hassan, A. M., El-Moneim, O. M. A., and Abdel-Aziem, S. H. (2015). Effectiveness of activated carbon and Egyptian montmorillonite in the protection against deoxynivalenol-induced cytotoxicity and genotoxicity in rats. Food Chem. Toxicol. 83, 174-182. doi: 10.1016/j.fct. 2015.06.015

Avantaggiato, G., Greco, D., Damascelli, A., Solfrizzo, M., and Visconti, A. (2014). Assessment of multi-mycotoxin adsorption efficacy of grape pomace. J. Agric. Food Chem. 62, 497-507. doi: 10.1021/jf404179h

Bräse, S., Gläser, F., Kramer, C., Lindner, S., Linsenmeier, A. M., Masters, K.-S., et al. (2013). "Progress in the chemistry of organic natural products," in The Chemistry of Mycotoxins, Vol. 97 (Vienna: Springer).

Carrott, P. J. M., and Carrott, M. R. (2007). Lignin-from natural adsorbent to activated carbon: a review. Bioresour. Technol. 98, 2301-2312. doi: 10.1016/j. biortech.2006.08.008

Chauhan, N., Tyagi, A. K., Kumar, P., and Malik, A. (2016). Antibacterial potential of Jatropha curcas synthesized silver nanoparticles against food borne pathogens. Front. Microbiol. 7:1748. doi: 10.3389/fmicb.2016. 01748

Chen, M. S., Pan, B. Z., Fu, Q., Tao, Y. B., Martínez-Herrera, J., Niu, L., et al. (2016). Comparative transcriptome analysis between gynoecious and monoecious plants identifies regulatory networks controlling sex determination in Jatropha curcas. Front. Plant Sci. 7:1953. doi: 10.3389/fpls.2016.01953 the availability of ZEA in media as a result of adsorption of ZEA. The study concluded that ACJC was a potent decontaminating agent for ZEA and could be used as an antidote against ZEAinduced toxicity. Thus, we demonstrated that the economically viable ACJC derived from plant source using an industrially upgradable technology can be a promising substitute for the commercially available AC in the market. We strongly believe that this work will have a great impact on the development of ecofriendly functional AC-based materials from natural resources for decontamination of mycotoxins.

\section{AUTHOR CONTRIBUTIONS}

NK, KKa, JA, ONG, VM, KKr, SC, and VG designed and interpreted the data of the work. NK, ONG, and VM drafted the work. All authors have approved the final version to be published.

\section{ACKNOWLEDGMENTS}

NK was grateful to the University Grants Commission, New Delhi, India, for providing the fellowship [File no: F. $2-14 / 2012$ (SA-I)] to pursue Ph.D. Authors were thankful to DRDO, Government of India, and DRDO-BU Center for Life Sciences for providing the instrument accessibility and acknowledged to NCCS for providing the cell line. Authors were also much thankful to Director of DFRL, Mysore, India, and Director of DRDO-BU Center for Life Sciences, Coimbatore, India, for their encouragement and support.

Correa, C. R., Otto, T., and Kruse, A. (2017). Influence of the biomass components on the pore formation of activated carbon. Biomass Bioenergy 97, 53-64. doi: 10.1016/j.biombioe.2016.12.017

Creppy, E. E. (2002). Update of survey, regulation and toxic effects of mycotoxins in Europe. Toxicol. Lett. 127, 19-28. doi: 10.1016/S0378-4274(01)00479-9

Dall'Asta, C., and Berthiller, F. (eds). (2015). Masked Mycotoxins in Food: Formation, Occurrence and Toxicological Relevance. London: Royal Society of Chemistry. doi: 10.1039/9781782622574

Dizbay-Onat, M., Vaidya, U. K., and Lungu, C. T. (2017). Preparation of industrial sisal fiber waste derived activated carbon by chemical activation and effects of carbonization parameters on surface characteristics. Ind. Crops Prod. 95, 583-590. doi: 10.1016/j.indcrop.2016.11.016

European Food Safety Authority [EFSA] (2004). Opinion of the scientific panel on contaminants in the food chain on a request from the commission related to zearalenone as undesirable substance in animal feed. EFSA J. 89, 1-35.

El-Sayed, G. O., Yehia, M. M., and Asaad, A. A. (2014). Assessment of activated carbon prepared from corncob by chemical activation with phosphoric acid. Water Resour. Ind. 7, 66-75. doi: 10.1016/j.wri.2014. 10.001

Galvano, F., Piva, A., Ritieni, A., and Galvano, G. (2001). Dietary strategies to counteract the effects of mycotoxins: a review. J. Food Prot. 64, 120-131. doi: 10.4315/0362-028X-64.1.120

Gamliel, A., Dehne, H. W., Karlovsky, P., and Fletcher, J. (2017). "Detection of mycotoxins in food: applications of rapid and reliable tools in a biosecurity context," in Practical Tools for Plant and Food Biosecurity, eds M. L. Gullino, J. P. Stack, J. Fletcher, and J. D. Mumford (Berlin: Springer International Publishing), 143-162.

Garcia-Recio, S., Pastor-Arroyo, E. M., Marín-Aguilera, M., Almendro, V., and Gascón, P. (2015). The transmodulation of HER2 and EGFR by substance P in 
breast cancer cells requires c-Src and metalloproteinase activation. PLOS ONE 10:e0129661. doi: 10.1371/journal.pone.0129661

Gottardi, D., Bukvicki, D., Prasad, S., and Tyagi, A. K. (2016). Beneficial effects of spices in food preservation and safety. Front. Microbiol. 7:1394. doi: 10.3389/ fmicb.2016.01394

Gromadzka, K., Waskiewicz, A., Chelkowski, J., and Golinski, P. (2008). Zearalenone and its metabolites: occurrence, detection, toxicity and guidelines. World Mycotoxin J. 1, 209-220. doi: 10.3920/WMJ2008.x015

Haugland, R. P., MacCoubrey, I. C., and Moore, P. L. (1994). Dual-fluorescence cell viability assay using ethidium homodimer and calcein AM. U.S. Patent No US 5314805 A. Washington, DC: U.S. Patent and Trademark Office.

Hsu, S. H., Huang, C. S., Chung, T. W., and Gao, S. (2014). Adsorption of chlorinated volatile organic compounds using activated carbon made from Jatropha curcas seeds. J. Taiwan Inst. Chem. Eng. 45, 2526-2530. doi: 10.1016/j. jtice.2014.05.028

IARC (1999). Overall evaluations of carcinogenicity to humans. IARC Monogr. $1-73,1-36$.

Iqbal, S. Z., Selamat, J., and Ariño, A. (2016). "Mycotoxins in food and food products: current status," in Food Safety, eds J. Selamat and S. Iqbal (Cham: Springer International Publishing), 113-123.

JECFA (2010). "In compendium of food additive specification (online edition); Food and Agriculture Organization of the United Nations (FAO)," in Proceedings of the 73rd Meeting of the Joint FAO/WHO Expert Committee on Food Additives, FAO JECFA Monographs 10, Rome.

Kalagatur, N. K., Mudili, V., Siddaiah, C., Gupta, V. K., Natarajan, G., Sreepathi, M. H., et al. (2015). Antagonistic activity of Ocimum sanctum L. essential oil on growth and zearalenone production by Fusarium graminearum in maize grains. Front. Microbiol. 6:892. doi: 10.3389/fmicb.2015.00892

Kowalska, K., Habrowska-Górczyńska, D. E., and Piastowska-Ciesielska, A. W. (2016). Zearalenone as an endocrine disruptor in humans. Environ. Toxicol. Pharmacol. 48, 141-149. doi: 10.1016/j.etap.2016.10.015

Kumar, A., and Sharma, S. (2008). An evaluation of multipurpose oil seed crop for industrial uses (Jatropha curcas L.): a review. Ind. Crops Prod. 28, 1-10. doi: 10.1016/j.indcrop.2008.01.001

Kumar, K. N., Venkataramana, M., Allen, J. A., Chandranayaka, S., Murali, H. S., and Batra, H. V. (2016). Role of Curcuma longa L. essential oil in controlling the growth and zearalenone production of Fusarium graminearum. LWT Food Sci. Technol. 69, 522-528. doi: 10.1016/j.lwt.2016.02.005

Lama, A. D., Kim, J., Martiskainen, O., Klemola, T., Salminen, J. P., Tyystjärvi, E., et al. (2016). Impacts of simulated drought stress and artificial damage on concentrations of flavonoids in Jatropha curcas (L.), a biofuel shrub. J. Plant Res. 129, 1141-1150. doi: 10.1007/s10265-016-0850-z

Lazzarini, A., Piovano, A., Pellegrini, R., Leofanti, G., Agostini, G., Rudić, S., et al. (2016). A comprehensive approach to investigate the structural and surface properties of activated carbons and related Pd-based catalysts. Catal. Sci. Technol. 6, 4910-4922. doi: 10.1039/C6CY00159A

Lemke, S. L., Grant, P. G., and Phillips, T. D. (1998). Adsorption of zearalenone by organophilic montmorillonite clay. J. Agric. Food Chem. 46, 3789-3796. doi: 10.1021/jf9709461

Li, Z. Q., Lu, C. J., Xia, Z. P., Zhou, Y., and Luo, Z. (2007). X-ray diffraction patterns of graphite and turbostratic carbon. Carbon 45, 1686-1695. doi: 10.1016/j.carbon.2007.03.038

Liu, B., Gu, J., and Zhou, J. (2016). High surface area rice husk-based activated carbon prepared by chemical activation with $\mathrm{ZnCl} 2-\mathrm{CuCl} 2$ composite activator. Environ. Prog. Sustain. Energy 35, 133-140. doi: 10.1002/ep.12215

Ooi, C. H., Cheah, W. K., Sim, Y. L., Pung, S. Y., and Yeoh, F. Y. (2017). Conversion and characterization of activated carbon fiber derived from palm empty fruit bunch waste and its kinetic study on urea adsorption. J. Environ. Manage. 197, 199-205. doi: 10.1016/j.jenvman.2017.03.083

Patra, J. K., and Baek, K. H. (2017). Antibacterial activity and synergistic antibacterial potential of biosynthesized silver nanoparticles against foodborne pathogenic bacteria along with its anticandidal and antioxidant effects. Front. Microbiol. 8:167. doi: 10.3389/fmicb.2017.00167

Patterson, A. L. (1939). The Scherrer formula for X-ray particle size determination. Phys. Rev. 56:978. doi: 10.1103/PhysRev.56.978

Ratnadass, A., and Wink, M. (2012). The phorbol ester fraction from Jatropha curcas seed oil: potential and limits for crop protection against insect pests. Int. J. Mol. Sci. 13, 16157-16171. doi: 10.3390/ijms131216157

Richard, J. L. (2007). Some major mycotoxins and their mycotoxicoses-An overview. Int. J. Food Microbiol. 119, 3-10. doi: 10.1016/j.ijfoodmicro.2007. 07.019

Riss, T. L., Moravec, R. A., Niles, A. L., Duellman, S., Benink, H. A., Worzella, T. J., et al. (2016). "Cell viability assays," in Assay Guidance Manual, eds G. S. Sittampalam, N. P. Coussens, K. Brimacombe, A. Grossman, M. Arkin, D. Auld et al (Bethesda, MD: Eli Lilly \& Company).

Sayğılı, H., and Güzel, F. (2016). High surface area mesoporous activated carbon from tomato processing solid waste by zinc chloride activation: process optimization, characterization and dyes adsorption. J. Clean. Prod. 113, 995-1004. doi: 10.1016/j.jclepro.2015.12.055

Scaduto, R. C., and Grotyohann, L. W. (1999). Measurement of mitochondrial membrane potential using fluorescent rhodamine derivatives. Biophys. J. 76, 469-477. doi: 10.1016/S0006-3495(99)77214-0

Sellamani, M., Kalagatur, N. K., Siddaiah, C., Mudili, V., Krishna, K., Natarajan, G., et al. (2016). Antifungal and zearalenone inhibitory activity of Pediococcus pentosaceus isolated from dairy products on Fusarium graminearum. Front. Microbiol. 7:890. doi: 10.3389/fmicb.2016. 00890

Senniappan, S., Palanisamy, S., Shanmugam, S., and Gobalsamy, S. (2016). Adsorption of $\mathrm{Pb}$ (II) from aqueous solution by Cassia fistula seed carbon: kinetics, equilibrium, and desorption studies. Environ. Prog. Sustain. Energy 36, 138-146. doi: 10.1002/ep.12466

Udomkun, P., Wiredu, A. N., Nagle, M., Bandyopadhyay, R., Müller, J., and Vanlauwe, B. (2017). Mycotoxins in Sub-Saharan Africa: present situation, socio-economic impact, awareness, and outlook. Food Control 72, 110-122. doi: 10.1016/j.foodcont.2016.07.039

Van Egmond, H. P., Schothorst, R. C., and Jonker, M. A. (2007). Regulations relating to mycotoxins in food. Anal. Bioanal. Chem. 389, 147-157. doi: 10.1007/s00216-007-1317-9

Vejdovszky, K., Schmidt, V., Warth, B., and Marko, D. (2017). Combinatory estrogenic effects between the isoflavone genistein and the mycotoxins zearalenone and alternariol in vitro. Mol. Nutr. Food Res. 61:1600526. doi: $10.1002 / \mathrm{mnfr} .201600526$

Venkataramana, M., Nayaka, S. C., Anand, T., Rajesh, R., Aiyaz, M., Divakara, S. T., et al. (2014). Zearalenone induced toxicity in SHSY-5Y cells: the role of oxidative stress evidenced by $\mathrm{N}$-acetyl cysteine. Food Chem. Toxicol. 65, 335-342. doi: 10.1016/j.fct.2013.12.042

Zinedine, A., Soriano, J. M., Molto, J. C., and Manes, J. (2007). Review on the toxicity, occurrence, metabolism, detoxification, regulations and intake of zearalenone: an oestrogenic mycotoxin. Food Chem. Toxicol. 45, 1-18. doi: 10.1016/j.fct.2006.07.030

Conflict of Interest Statement: The authors declare that the research was conducted in the absence of any commercial or financial relationships that could be construed as a potential conflict of interest.

Copyright (c) 2017 Kalagatur, Karthick, Allen, Nirmal Ghosh, Chandranayaka, Gupta, Krishna and Mudili. This is an open-access article distributed under the terms of the Creative Commons Attribution License (CC BY). The use, distribution or reproduction in other forums is permitted, provided the original author(s) or licensor are credited and that the original publication in this journal is cited, in accordance with accepted academic practice. No use, distribution or reproduction is permitted which does not comply with these terms. 